\title{
Taxa de geração de viagens para instituições privadas de ensino superior: estudo de caso para a cidade de Uberlândia-MG
}

\author{
Ana Flávia Ferreira de Castro Paula ${ }^{1}$, José Aparecido Sorratini ${ }^{2}$, Thays Pereira Silva ${ }^{3}$, \\ Maria Amélia Mangussi Nogueira ${ }^{4}$ e Ana Carolina Souza Silva ${ }^{5}$
}

\begin{abstract}
Resumo: O objetivo deste estudo foi estimar as taxas de geração de viagens para modos de transporte motorizado e não motorizado, utilizados por alunos, professores e funcionários de instituições privadas de ensino superior na cidade de Uberlândia, Minas Gerais. Foi possível estimar as taxas somente para alunos e no turno noturno. As taxas médias de atração/produção obtidas para os modos de transporte automóvel, a pé, motocicleta, ônibus urbano, ônibus interurbano e van, foram, respectivamente de $0,280 / 0,283 ; 0,005 / 0,006 ; 0,180 / 0,179 ; 0,335 / 0,316 ; 0,093 / 0,103$ e 0,050/0,063. No que diz respeito ao coeficiente de variação, para os modos de transporte automóvel e ônibus urbano, os valores percentuais para atração/produção, foram respectivamente de 13,23/11,44 e 20,53/25,19, indicando boa precisão dos resultados obtidos. Para os demais modos de transporte estudados, a pé, motocicleta, ônibus interurbano e van, o coeficiente de variação ficou entre 38,11\% e 70,71\%, indicando baixa precisão na determinação das taxas de geração de viagens.
\end{abstract}

Palavras-chave: polo gerador de viagem, instituição de ensino superior, taxas de geração de viagens.

\begin{abstract}
The aim of this study was to estimate the trip generation rates for the motorized and non-motorized transportation modes used by students, faculty members and staff of private Universities in the city of Uberlândia, Brazil. The rates were estimated only for students and for the evening period. The average rates of attraction/production obtained for the transportation modes car, on foot, motorcycle, urban bus, intercity bus and van were: $0.280 / 0.283,0.005 / 0.006,0.180 / 0.179$, 0.335/0.316, 0.093/0.103 and 0.050/0.063, respectively. The coefficient of variation for the transportation modes car and urban bus, in percent values of attraction/production, were: 13.23/11.44 and 20.53/25.19, respectively, indicating good precision of the results. All other transportation modes analyzed: on foot, motorcycle, intercity bus and van, the coefficient of variation was between $38.11 \%$ and $70.71 \%$, indicating low precision in the determination of trip generation rates.
\end{abstract}

Keywords: trip generators, private universities, trip generation rates.

\section{INTRODUÇÃO}

As Instituições de Ensino Superior (IES) são consideradas importantes Polos Geradores de Viagens (PGV), por promoverem um elevado número de viagens, oriundas do deslocamento realizado por alunos, professores e funcionários, nos mais diferentes modos de transporte. Segundo Bertazzo et al. (2012), tais viagens, ou suas taxas, são elementos essenciais em estudos relacionados com o impacto que essas instituições produzem sobre a circulação e o tráfego de veículos e pessoas no seu entorno.

O Código de Trânsito Brasileiro (Brasil, 1997), no artigo 93, estabelece que nenhum projeto de edificação que possa transformar-se em um polo atrativo de trânsito será aprovado sem prévia anuência do órgão ou entidade responsável, com circunscrição sobre a via e sem que, no projeto, conste área adequada para estacionamento e indicação das vias de acesso. No caso das instituições de ensino, os órgãos gestores responsáveis pela aprovação de tais projetos não possuem ferramentas específicas capazes de identificar as

\footnotetext{
${ }^{1}$ Ana Flávia Ferreira de Castro Paula. Centro Universitário do Triângulo UNITRI. (anaffc@yahoo.com.br)

2 José Aparecido Sorratini. Universidade Federal de Uberlândia - UFU,

Faculdade de Engenharia Civil - FECIV. (sorratin@ufu.br)

3 Thays Pereira Silva. Centro Universitário do Triângulo - UNITRI.

(thayspereira@live.com)

${ }^{4}$ Maria Amélia Mangussi Nogueira. Centro Universitário do Triângulo -

UNITRI. (mmangussi@hotmail.com)

${ }^{5}$ Ana Carolina Souza Silva. Centro Universitário do Triângulo - UNITRI.

(ana.carolinass@hotmail.com)
}

Manuscrito recebido em 15/11/2014 e aprovado para publicação em 06/05/2015.

Este artigo é parte de TRANSPORTES v. 23, n. 2, 2015. ISSN: 2237-1346 (online). DOI: 10.14295/transportes.v23i2.865 viagens geradas por esses empreendimentos, sobretudo de forma desagregada por modo de transporte.

Segundo Souza (2007), nas instituições privadas, a maioria das viagens é realizada por automóvel, o que causa impactos significativos no trânsito nas suas imediações. Tais impactos são acentuados pelo fato dos horários de início e término das aulas, em geral, coincidirem com os períodos de pico do tráfego.

Para que os estudos de impacto de PGVs no sistema viário do seu entorno sejam possíveis, é necessária a determinação das taxas de geração de viagens. Jacques et al. (2011), em publicação voltada para polos geradores de viagens nas instituições de ensino superior (ensino profissional de nível superior e ensino superior propriamente dito), compilaram taxas de geração de viagens definidas pelo ITE (2008). Além da indicação da variável dependente (y) e da variável independente (x) de cada taxa, são apresentados o dia e o horário de realização da pesquisa, a quantidade de estudos em cada caso, o número médio da variável independente, a distribuição direcional, a taxa média de geração e seu desvio padrão.

As taxas de geração de viagens definem uma relação direta entre o total de viagens geradas em cada instituição e características observadas nas mesmas, no intuito de estimar viagens para um novo empreendimento (Bertazzo, 2008). Para Souza (2007), o total de viagens atraídas e produzidas de cada instituição é determinado por meio da adição das viagens específicas e das viagens desviadas.

Segundo Jacques et al. (2011), a TECTRAN - Técnicos em Transportes Ltda. tem realizado, dentre outros, estudos voltados à estimativa do número de viagens atraídas e produzidas por instituições de ensino superior. Nos estudos realizados pela empresa, são empregados modelos de 
geração de viagens elaborados para o caso específico analisado ou definidos em estudos realizados em instituições com características semelhantes. Eles utilizam taxas de geração de viagens diárias, fatores horários de pico para as viagens atraídas e produzidas, percentagens das viagens por modo de transporte e taxa de ocupação dos veículos (automóvel, ônibus e, em alguns casos, vans). Os modelos e parâmetros empregados foram determinados com base em contagens volumétricas classificadas nas entradas dos PGVs e em levantamentos junto aos usuários das instituições para identificação da origem e destino das viagens, modo de transporte utilizado, dentre outras características. A dimensão temporal do estudo deu-se ao longo de um dia normal de funcionamento de uma instituição de ensino superior, considerando como horário de pico o horário de início de funcionamento dos turnos das instituições, o que corresponde aos horários de pico do sistema viário.

Em estudo realizado no Distrito Federal, Souza (2007) obteve taxas e produziu modelos de geração de viagens para os principais modos de transporte (automóvel, a pé e ônibus), utilizados pelos usuários de instituições de ensino superior. Diante da dificuldade encontrada na coleta dos dados, a autora avaliou como variável explicativa somente o número de alunos matriculados. Neste estudo, ela obteve taxas de geração de viagem para todos os cursos das instituições, denominadas por global, e para dois cursos, em específico, medicina e administração.

O número de estudos voltados para a estimativa de taxas de geração de viagens em instituições de ensino superior privadas ainda é bastante reduzido no Brasil. Diante disso, estudos relacionados a este tema são importantes, pois podem contribuir significativamente no planejamento viário das cidades brasileiras. Nesse sentido, esta pesquisa tem por objetivo estimar taxas de geração de viagens para instituições privadas de ensino superior para a cidade de Uberlândia, MG.

\section{ESTRUTURA METODOLÓGICA: DEFINIÇÃO DAS TAXAS DE GERAÇÃO DE VIAGENS POR MODO DE TRANSPORTE}

As instituições pesquisadas, o tamanho da amostra a ser coletada e o modo de coleta dos dados necessários para atender aos objetivos desta pesquisa estão detalhados em Paula et al. (2014). No citado artigo, os autores objetivavam caracterizar o padrão de viagens geradas em quatro Instituições de Ensino Superior (IES) privadas, dentre as dez existentes na cidade de Uberlândia-MG. As informações geradas por Paula et al. (2014), especificamente o número de viagens atraídas e produzidas pelos usuários das IES, permitiu a realização deste estudo, cuja análise se concentra na determinação das taxas de geração de viagens geradas por alunos, funcionários e professores.

A coleta dos dados dos usuários das IES foi realizada por meio de um questionário aplicado aos alunos, professores e funcionários das mesmas, cujo modelo pode ser visualizado em Paula (2013).

Neste estudo, as taxas de geração de viagens foram calculadas em função das viagens atraídas (Equação 1) e produzidas (Equação 2) por alunos, bem como as viagens atraídas (Equação 3) e produzidas (Equação 4) por professores e funcionários das IES. Essa análise foi realizada para cada turno de trabalho, manhã, tarde e noite e para cada modo de transporte, motorizado e não motorizado.

$$
T G V A=\frac{N V A}{N A}
$$

em que:

TGVA = taxa de geração de viagens atraídas por turno de funcionamento (horário pico do polo gerador: manhã ou tarde ou noite);

NVA = número de viagens atraídas por turno de funcionamento; e

$\mathrm{NA}=$ número de alunos matriculados por turno de funcionamento.

$$
T G V P=\frac{N V P}{N A}
$$

em que:

TGVP = taxa de geração de viagens produzidas por turno de funcionamento (horário pico do polo gerador: manhã ou tarde ou noite); e

NVP = número de viagens produzidas por turno de funcionamento.

$$
T G V A=\frac{N V A}{N P F}
$$

em que:

$\mathrm{NPF}=$ número de professores e funcionários por turno de funcionamento.

$$
T G V P=\frac{N V P}{N P F}
$$

Para o cálculo das taxas de geração de viagens, optou-se por agrupar alguns modos de transporte, tendo em vista a semelhança dos usos. As viagens de automóvel feitas à instituição, por exemplo, como motorista, de carona, ou tendo sido levado/buscado foram todas agrupadas no modo automóvel. Para os demais modos: a pé, bicicleta, motocicleta, ônibus urbano, ônibus interurbano e van não houve necessidade de agrupamento.

É importante ressaltar que as taxas de geração de viagens para os modos de transporte tais como ônibus urbano, ônibus interurbano, van, motocicleta, a pé e bicicleta foram obtidas em função da quantidade individualizada de viagens geradas por esses modos, independente da categoria da viagem. Por outro lado, para o modo de transporte automóvel, as taxas de geração de viagens foram aquelas obtidas para os veículos. Especificamente para as viagens veiculares (automóvel), foi tomada a soma das viagens específicas com as viagens desviadas, desconsiderando-se as viagens de passagem.

As viagens específicas são aquelas que o usuário tem a instituição de ensino como local de destino, ou seja, são as viagens realizadas com o único objetivo de atingir a instituição (Bertazzo, 2008). No questionário aplicado aos usuários, no que diz respeito ao modo de transporte automóvel, foi feita uma análise particular para essas viagens, visto que o usuário que utilizou o modo de transporte automóvel (carona ou automóvel alguém o levou/buscou na instituição) para se deslocar até a mesma, utilizou o mesmo veículo do motorista para fazer esse deslocamento. Assim, por meio da aplicação do questionário, foi possível obter a quantidade de viagens específicas atraídas e produzidas pelo modo de transporte automóvel. 
As viagens desviadas são aquelas realizadas por automóvel, cujo condutor do veículo não é usuário da instituição, ele apenas leva ou busca um usuário desviando o seu trajeto original para atingir o objetivo que é a IES (Bertazzo, 2008). Por meio da aplicação do questionário, foi possível obter a quantidade de viagens desviadas utilizando o modo de transporte automóvel (alguém levou/buscou na instituição).

As viagens de passagem são aquelas realizadas pelo condutor do veículo que não é usuário da instituição, ele apenas leva ou busca o usuário e não desvia do seu trajeto original, ou seja, o condutor passaria pela IES de qualquer maneira (Bertazzo, 2008). É importante ressaltar que as viagens consideradas de passagem não são contabilizadas no volume de tráfego ocasionado pelo polo gerador de viagens, uma vez que o condutor já faz o trajeto, independente da instituição estar ou não inserida no seu local da passagem.

Uma vez definido o total das viagens atraídas e produzidas, determinou-se o coeficiente de expansão para cada turno. O coeficiente foi obtido por meio da razão entre o número de alunos matriculados e o número de questionários aplicados em cada turno de funcionamento da instituição.

\section{ANÁLISE DOS RESULTADOS}

Neste trabalho, foram avaliadas quatro Instituições de Ensino Superior (IES) localizadas na cidade de Uberlândia-MG, denominadas de IES-A, IES-B, IES-C e IES-D. As instituições analisadas concentram suas atividades no ensino de graduação presencial e a maioria dos seus alunos frequenta as aulas no período noturno. Verificou-se que a IES-A possuía na época da pesquisa, em 2012, 6.682 alunos matriculados, 200 professores e 250 funcionários e oferecia
20 cursos de graduação, nos três turnos, manhã (M), tarde (T) e noite (N). A IES-B possuía 2.083 alunos matriculados, 90 professores e 184 funcionários e oferecia 11 cursos de graduação, todos no período noturno. A IES-C possuía 1.729 alunos matriculados, 65 professores e 163 funcionários e oferecia 15 cursos, nos períodos matutino e noturno. A IES-D possuía 1.198 alunos matriculados, 100 professores e 30 funcionários e oferecia 9 cursos, nos três turnos.

Na Tabela 1, são apresentados o número total de alunos, professores, funcionários e a amostra necessária de questionários aplicados nas IES-A, B, C e D. Conforme Paula (2013), a amostra necessária é definida como o número de questionários a serem aplicados, no intuito de atender ao erro amostral máximo estipulado nesta pesquisa (5\%), corrigido em função do número total de alunos matriculados no turno. Os professores e funcionários não foram avaliados por turno, visto que a maioria dos indivíduos não tinha o seu trabalho caracterizado em um único período do dia.

Com base na Tabela 1, verifica-se que a atividade acadêmica nas instituições A, C e D se concentra no período noturno e na IES-B, é exclusivamente nesse período. Nas Tabelas 2 a 4 estão reunidos os dados populacionais pesquisados e os erros amostrais calculados para alunos, professores e funcionários, respectivamente, independente do turno de funcionamento. Analisando a Tabela 2, verifica-se que apenas nas IES-B e D o valor do erro amostral calculado para as instituições ficou acima, porém próximo, daquele inicialmente estipulado de 5\%.

Para professores e funcionários (Tabela 3 e 4), o erro amostral ficou muito acima daquele máximo tolerado neste trabalho (5\%). O resultado pode ser explicado pelo baixo

Tabela 1. Dados do número total de alunos matriculados, professores e funcionários e a amostra necessária de questionários aplicados nas IES-A, B, C e D.

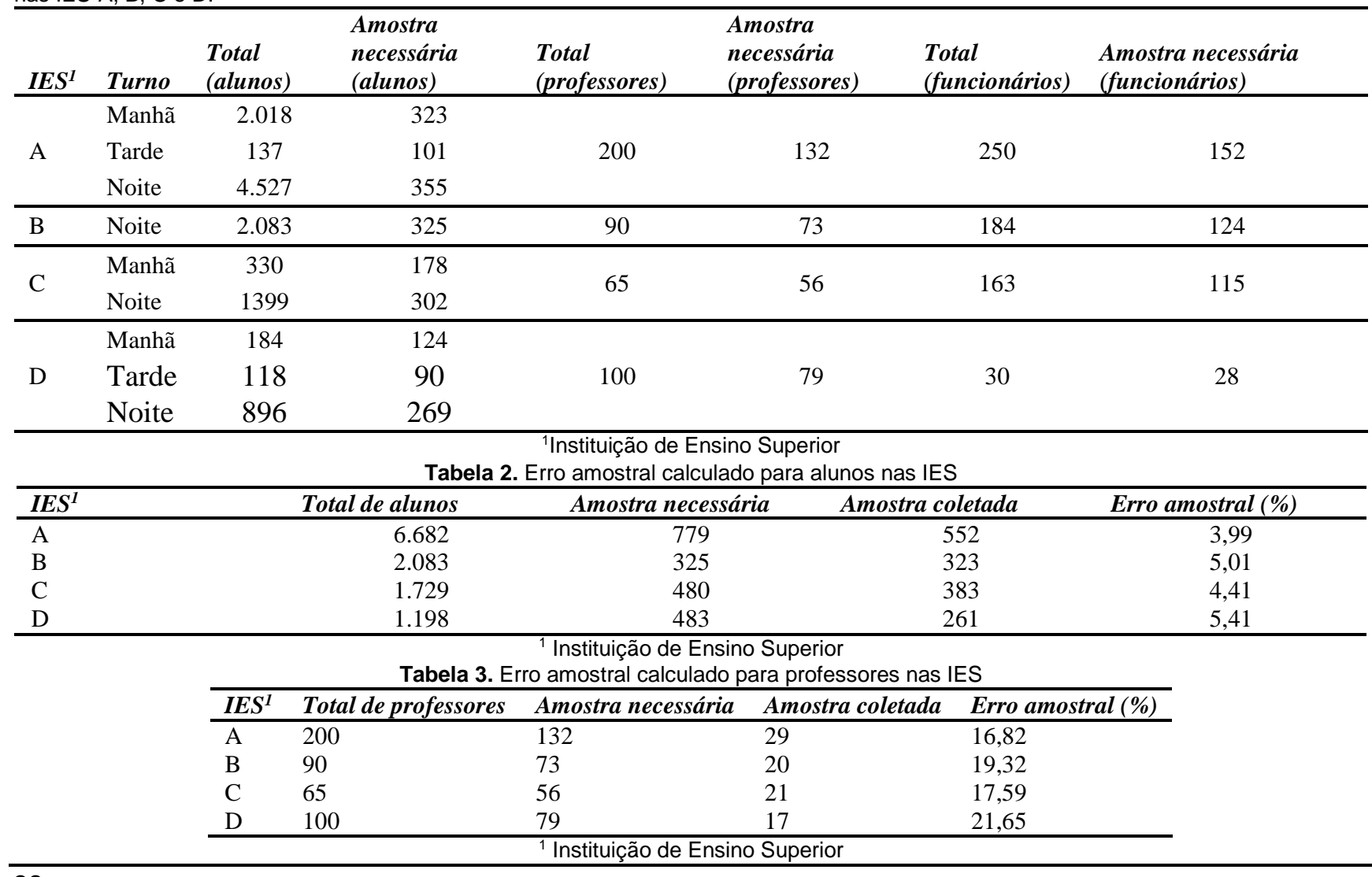


Tabela 4. Erro amostral calculado para funcionários nas IES

\begin{tabular}{lllll}
\hline IES $^{\mathbf{1}}$ & Total de funcionários & Amostra necessária & Amostra coletada & Erro amostral (\%) \\
\hline A & 250 & 152 & 101 & 7,52 \\
B & 184 & 124 & 9 & 31,85 \\
C & 163 & 115 & 25 & 18,03 \\
D & 30 & 28 & 19 & 13,61 \\
\hline \multicolumn{5}{c}{ Instituição de Ensino Superior }
\end{tabular}

número de questionários preenchidos por esses profissionais. Observou-se, também, que um dos fatores que contribuíram para a baixa quantidade de questionários respondidos pelos professores foi a não permanência dos mesmos nas instituições, por não trabalharem em tempo integral. Em função disso, os dados referentes aos professores e funcionários não foram analisados neste trabalho. Situação semelhante foi verificada por Souza (2007) e Bertazzo (2008), que analisaram o padrão de viagens geradas para instituições de ensino superior e médio, respectivamente, em Brasília -DF.

\subsection{Taxas de geração de viagens}

As taxas de geração de viagens foram calculadas em função das viagens atraídas e produzidas por aluno, por turno e para os modos de transporte motorizado (automóvel, motocicleta, ônibus urbano, ônibus interurbano e van) e não motorizado (a pé e bicicleta). Especificamente para as viagens que utilizam o modo de transporte automóvel, foi considerada a soma das viagens específicas com as viagens desviadas, sendo, portanto, desconsideradas, as viagens de passagem, conforme apresentado na Tabela 5.

A partir das viagens atraídas e produzidas realizadas pelos alunos, foram calculados os erros amostrais e os coeficientes de expansão em cada turno de funcionamento das IES (Tabela 6). Quando analisado o erro amostral independentemente do turno (Tabela 2), os valores obtidos apresentaram-se abaixo ou próximo do estipulado (5\%), mostrando que o número de questionários respondidos pelos alunos atendeu ao inicialmente estipulado para as instituições. No entanto, quando analisada cada IES por turno, o erro amostral sofreu alteração (Tabela 6), indicando que em algumas instituições e em alguns turnos, a quantidade de questionários respondidos pelos alunos não atingiu a quantidade mínima exigida, provocando um erro acima de $5 \%$. Por outro lado, em outras IES e turnos esse valor foi ultrapassado, indicando um erro abaixo de $5 \%$.

Analisando a Tabela 6, nota-se que o erro amostral calculado para as IES-A, C e D no turno da manhã, IES-A e D no turno da tarde e IES-D no turno da noite, apresentaram-se muito acima do valor aqui estipulado, que é de $5 \%$. Erro amostral acima de 5\% indica, neste trabalho, que o número de questionários respondidos em cada turno é insuficiente para explicar o comportamento dos alunos matriculados naquele turno. Diante disso, optou-se por não calcular seus respectivos coeficientes de expansão e consequentemente, suas taxas de geração de viagens atraídas e produzidas, pois a partir de uma amostra insuficiente, as taxas obtidas por meio da mesma poderão apresentar-se equivocadas.

O coeficiente de expansão foi multiplicado pelo número total de viagens atraídas ou produzidas em cada turno, para que se pudesse expandir o resultado para toda a população de alunos matriculados no turno.

Na Tabela 7 são apresentados os dados expandidos por modo de transporte, para as viagens atraídas e produzidas, respectivamente.

A Tabela 8 reúne os resultados encontrados para as taxas de atração e produção de viagens, para os modos de transportes automóvel, a pé, bicicleta, motocicleta, ônibus urbano, ônibus interurbano e van, determinadas por meio

Tabela 5. Viagens veiculares atraídas e produzidas por alunos e por categoria para as IES

\begin{tabular}{|c|c|c|c|c|c|c|c|c|c|}
\hline \multirow[b]{2}{*}{ IES $S^{1}$} & \multirow[b]{2}{*}{ Turno } & \multicolumn{3}{|c|}{ Viagens atraídas } & \multirow[b]{2}{*}{ Total de viagens atraídas ${ }^{5}$} & \multicolumn{3}{|c|}{ Viagens produzidas } & \multirow[b]{2}{*}{ Total de viagens produzidas ${ }^{5}$} \\
\hline & & Espec. $^{2}$ & Desv. $^{3}$ & Pass. $^{4}$ & & Espec. & Desv. & Pass. & \\
\hline \multirow{3}{*}{ A } & Manhã & 46 & 3 & 7 & 49 & 28 & 3 & 3 & 31 \\
\hline & Tarde & 3 & 0 & 0 & 3 & 15 & 1 & 0 & 16 \\
\hline & Noite & 85 & 0 & 4 & 85 & 88 & 2 & 3 & 90 \\
\hline $\bar{B}$ & Noite & 87 & 3 & 0 & 90 & 85 & 3 & 1 & 88 \\
\hline \multirow{2}{*}{$\mathrm{C}$} & Manhã & 18 & 0 & 0 & 18 & 18 & 0 & 0 & 18 \\
\hline & Noite & 113 & 1 & 1 & 114 & 114 & 1 & 1 & 115 \\
\hline \multirow{3}{*}{ D } & Manhã & 12 & 2 & 4 & 14 & 12 & 1 & 3 & 13 \\
\hline & Tarde & 0 & 0 & 0 & 0 & 1 & 0 & 0 & 1 \\
\hline & Noite & 58 & 5 & 1 & 63 & 60 & 7 & 5 & 67 \\
\hline
\end{tabular}

${ }^{1}$ Instituição de Ensino Superior; ${ }^{2}$ Específicas; ${ }^{3}$ Desviadas; ${ }^{4}$ Passagem; ${ }^{5}$ Soma das viagens específicas com as viagens desviadas.

Tabela 6. Cálculo do erro amostral e do coeficiente de expansão por turno para as IES, em função do número de alunos matriculados.

\begin{tabular}{lllccc}
\hline IES $^{\mathbf{1}}$ & Turno & NAM $^{\mathbf{2}}$ & Amostra coletada & Erro amostral & Coeficiente de expansão \\
\hline \multirow{3}{*}{ A } & Manhã & 2018 & 176 & 7,06 & --- \\
\cline { 2 - 6 } & Tarde & 137 & 26 & 17,72 & --- \\
\cline { 2 - 6 } & Noite & 4527 & 350 & 5,02 & 12,93 \\
\hline B & Noite & 2083 & 323 & 5,01 & 6,45 \\
\hline \multirow{2}{*}{ C } & Manhã & 330 & 23 & 19,71 & --- \\
& Noite & 1399 & 360 & 4,45 & 3,89 \\
\hline \multirow{4}{*}{ D } & Manhã & 184 & 50 & 12,16 & --- \\
& Tarde & 118 & 4 & 48,16 & --- \\
& Noite & 896 & 207 & 5,97 & -- \\
\hline
\end{tabular}

${ }^{1}$ Instituição de Ensino Superior; ${ }^{2}$ Número de alunos matriculados; --- = dado numérico não calcula do. 
PAULA, A. F. F. C.; SORRATINI, J. A.; SILVA, T. P.; NOGUEIRA, M. A. M.; SILVA, A.C.

Tabela 7. Dados expandidos por modo de transporte para as viagens atraídas e produzidas, em função do número de alunos matriculados.

\begin{tabular}{|c|c|c|c|c|c|c|c|c|c|}
\hline \multirow[b]{2}{*}{$I_{E} S^{1}$} & \multirow[b]{2}{*}{ Turno } & \multirow[b]{2}{*}{$N A M^{2}$} & \multicolumn{7}{|c|}{ Modos de transporte } \\
\hline & & & Automóvel & A pé & Bicicleta & Motocicleta & $\begin{array}{l}\text { Ônibus } \\
\text { urbano }\end{array}$ & $\begin{array}{l}\text { Ônibus interur- } \\
\text { bano }\end{array}$ & Van \\
\hline \multicolumn{10}{|c|}{ Número de viagens atraídas } \\
\hline A & Noite & 4527 & 1099 & 26 & 0 & 427 & 1798 & 608 & 336 \\
\hline B & Noite & 2083 & 581 & 6 & 6 & 445 & 722 & 142 & 77 \\
\hline $\mathrm{C}$ & Noite & 1399 & 443 & 0 & 0 & 323 & 365 & 109 & 54 \\
\hline \multicolumn{10}{|c|}{ Número de viagens produzidas } \\
\hline A & Noite & 4527 & 1164 & 39 & 0 & 414 & 1733 & 698 & 453 \\
\hline B & Noite & 2083 & 568 & 6 & 6 & 445 & 703 & 155 & 84 \\
\hline $\mathrm{C}$ & Noite & 1399 & 447 & 0 & 0 & 326 & 319 & 113 & 70 \\
\hline
\end{tabular}

Tabela 8. Taxas de geração de viagens atraídas e produzidas para diferentes modos de transportes realizados por alunos, nos diferentes turnos de funcionamento das IES.

\begin{tabular}{|c|c|c|c|c|c|c|c|c|}
\hline \multirow[b]{2}{*}{ Turno $^{1}$} & \multirow[b]{2}{*}{ IES $S^{2}$} & \multicolumn{7}{|c|}{ Modos de transportes } \\
\hline & & Automóvel & A pé & Bicicleta & Motocicleta & Ônibus urbano & Ônibus interurbano & Van \\
\hline \multicolumn{9}{|c|}{ Taxas de geração de viagens atraídas } \\
\hline \multirow{6}{*}{ Noite } & A & 0,243 & 0,006 & --- & 0,094 & 0,397 & 0,134 & 0,074 \\
\hline & B & 0,279 & 0,003 & 0,003 & 0,214 & 0,347 & 0,068 & 0,037 \\
\hline & $\mathrm{C}$ & 0,317 & --- & --- & 0,231 & 0,261 & 0,078 & 0,039 \\
\hline & Média $^{3}$ & 0,280 & 0,005 & --- & 0,180 & 0,335 & 0,093 & 0,050 \\
\hline & D. Padrão ${ }^{4}$ & 0,037 & 0,002 & --- & 0,075 & 0,069 & 0,036 & 0,021 \\
\hline & C.V. $(\%)^{5}$ & 13,23 & 47,14 & --- & 41,56 & 20,53 & 38,11 & 41,62 \\
\hline \multicolumn{9}{|c|}{ Taxas de geração de viagens produzidas } \\
\hline \multirow{6}{*}{ Noite } & A & 0,257 & 0,009 & --- & 0,091 & 0,383 & 0,154 & 0,100 \\
\hline & B & 0,272 & 0,003 & 0,003 & 0,214 & 0,337 & 0,074 & 0,040 \\
\hline & $\mathrm{C}$ & 0,319 & --- & --- & 0,233 & 0,228 & 0,081 & 0,050 \\
\hline & Média $^{3}$ & 0,283 & 0,006 & --- & 0,179 & 0,316 & 0,103 & 0,063 \\
\hline & D. Padrão ${ }^{4}$ & 0,032 & 0,004 & --- & 0,077 & 0,080 & 0,044 & 0,032 \\
\hline & C.V. $(\%)^{5}$ & 11,44 & 70,71 & --- & 42,99 & 25,19 & 43,02 & 50,76 \\
\hline
\end{tabular}

${ }^{1}$ Refere-se ao horário de pico do polo gerador (manhã ou tarde ou noite); ${ }^{2}$ Instituição de Ensino Superior; ${ }^{3,4,5}$ Respectivamente, média, desvio padrão e coeficiente de variação das taxas obtidas em cada turno; --- = dado numérico não calculado.

das Equações 1 e 2. Estas taxas foram obtidas considerando o número de viagens atraídas por turno de funcionamento da IES (manhã ou tarde ou noite), em função do número de alunos matriculados em cada turno.

No que diz respeito ao período noturno, a taxa média obtida para o modo automóvel foi de 0,280 e 0,283 para viagens atraídas e produzidas, respectivamente. Um ponto importante a ressaltar, são os baixos valores do desvio padrão e, consequentemente, do coeficiente de variação (0,037 e 13,23\% para atração e 0,032 e 11,44\% para produção), indicando um bom grau de homogeneidade das taxas obtidas.

Souza (2007) estimou taxas para instituições de ensino superior de Brasília-DF. A autora obteve resultados para o modo automóvel no turno noturno em duas IES, encontrando valores de 0,61 e 0,23 (média de 0,42), e 0,58 e 0,25 (média de 0,41) para viagens atraídas e produzidas, respectivamente. Analisando seus resultados, nota-se semelhança com os dados obtidos neste trabalho somente em uma das instituições pesquisadas pela autora, sendo o valor médio muito discrepante daqueles aqui estimados.

Com relação ao modo de transporte a pé, os resultados médios obtidos neste trabalho, para viagens atraídas e produzidas foram, respectivamente, 0,005 e 0,006. Contudo, esses resultados devem ser vistos com cautela, pois o coeficiente de variação para o turno em análise e tipos de viagens foi muito elevado, o que mostra a heterogeneidade das taxas individuais de cada IES.

Souza (2007) também estimou taxas de geração de viagens em duas instituições de ensino superior de BrasíliaDF, para o modo de transporte a pé. Resultado semelhante foi constatado no turno da noite, onde os resultados para atração foram de 0,02 e 0,11 (média de 0,065), e para produção, foram encontrados 0,02 e 0,12 (média de 0,07). Apesar da autora não explicitar os dados estatísticos como desvio padrão e coeficiente de variação, pode-se inferir pelos dados apresentados que o coeficiente de variação dos mesmos, se calculado, seria muito elevado. Essa condição corrobora aquela encontrada para este meio de transporte investigado neste trabalho.

Ao se analisar o modo de transporte bicicleta (Tabela 8), nota-se que para as IES-A e C, não foi possível estimar nenhuma taxa (atraída ou produzida), visto que não houve usuários para esse modo de locomoção no período analisado. Contudo, foi possível estimar uma taxa de 0,003 , tanto para atração quanto para produção, somente para a IES-B. Os baixos valores das taxas desse modo de transporte podem ser explicados pelo fato da maioria dos alunos do turno noturno apresentar a característica de trabalhar o dia todo, e 
quase sempre, o trabalho exige uniforme ou outra vestimenta mais formal, sendo que seu uso desestimula o uso da bicicleta. Outro fato importante a destacar, diz respeito à localização da IES, particularmente as IES-A e C, em relação aos bairros residenciais e do centro da cidade. Essa situação também desestimula os alunos a utilizarem a bicicleta e estimula-os, por outro lado, a utilizarem outros modos como o automóvel e ônibus urbano.

Os resultados estimados para o meio de transporte motocicleta estão compilados na Tabela 8. Analisando-a, nota-se que os valores médios de taxas de atração e produção foram de 0,180 e 0,179 . Os coeficientes de variação para esse modo de transporte variaram entre $41,56 \%$ e 42,99\%, considerados elevados, mostrando heterogeneidade das taxas entre as IES.

Com relação ao modo de transporte ônibus urbano (Tabela 8), verificaram-se taxas médias de geração de viagens atraídas e produzidas, respectivamente, de 0,335 e 0,316. O baixo coeficiente de variação (20,53\% para viagens atraídas e $25,19 \%$ para produzidas) mostra a homogeneidade das taxas estimadas entre as IES pesquisadas.

Souza (2007) estimou taxas de geração de viagens em duas instituições de ensino superior para o modo de transporte ônibus urbano. Considerando o turno da noite, os resultados para atração foram de 0,14 e 0,45 (média de 0,29), e para produção, foram encontrados 0,10 e 0,35 (média de $0,22)$.

Neste trabalho, também foram estimadas taxas de geração de viagens para o modo de transporte ônibus interurbano (Tabela 8). Esse tipo de transporte é bastante usado por estudantes residentes em cidades vizinhas, as quais não oferecem o aporte educacional disponível na cidade de Uberlândia-MG. Analisando a Tabela 8, verificam-se, para este modo de transporte, taxas médias de geração de viagens atraídas e produzidas, respectivamente, de 0,093 e 0,103 para o turno da noite.

Além dos modos de transporte automóvel, a pé, bicicleta, motocicleta, ônibus urbano e ônibus interurbano, neste trabalho, as taxas de geração de viagens também foram estimadas para o modo de transporte van (Tabela 8). Assim como o ônibus interurbano, esse tipo de transporte é bastante usado por estudantes residentes em cidades vizinhas à Uberlândia-MG. Analisando os dados obtidos, verificam-se taxas médias de geração de viagens atraídas e produzidas, respectivamente, de 0,050 e 0,063. O coeficiente de variação estimado é alto, variando de 41,62\% a 50,76\%, indicando heterogeneidade entre as taxas individuais obtidas em cada IES.

A estimativa das taxas de geração de viagens para os modos de transporte ônibus interurbano e van são importantes para o órgão gestor de trânsito do município. Essas informações podem auxiliar na estimativa e locação de estacionamento ou ponto de embarque/desembarque para esses tipos de veículos, dado a especificidade de seu porte e impacto negativo que pode causar no trânsito adjacente à instituição de ensino.

\section{CONCLUSÕES}

A partir dos dados analisados e do objetivo proposto, pôde-se concluir que as taxas médias de atração/produção obtidas por alunos no período noturno, para os modos de transporte automóvel, a pé, motocicleta, ônibus urbano, ônibus interurbano e van, foram, respectivamente de 0,280/0,283; $\quad 0,005 / 0,006 ; \quad 0,180 / 0,179 ; \quad 0,335 / 0,316$; $0,093 / 0,103$ e $0,050 / 0,063$. No que diz respeito ao coeficiente de variação, para os modos de transporte automóvel e ônibus urbano, os valores (em percentual) para atração/produção, foram respectivamente de 13,23/11,44 e 20,53/25,19, indicando boa precisão dos resultados obtidos. Para os demais modos de transporte estudados a pé, motocicleta, ônibus interurbano e van o coeficiente de variação ficou entre $38,11 \%$ e $70,71 \%$, indicando baixa precisão na determinação das taxas de geração de viagens, o que recomenda cautela na utilização dos valores citados. Para o modo de transporte bicicleta, não foi possível estimar uma taxa média, e muito menos desvio padrão e coeficiente de variação, pois foram verificados usuários somente em uma instituição de ensino superior.

Nas IES que oferecem cursos nos turnos da manhã e da tarde, o erro amostral verificado ficou acima do estipulado como aceitável neste trabalho (5\%), indicando que o número de alunos que responderam ao questionário não atingiu o número mínimo de respondentes exigidos nas condicionantes estatísticas. Diante disso, não foram estimadas as taxas de geração de viagens atraídas e produzidas, nesses dois turnos, para os diferentes modos de transporte analisados, pois a partir de uma amostra insuficiente, as taxas obtidas por meio da mesma poderão estar totalmente erradas. O erro amostral acima de $5 \%$ também foi o motivo de não terem sido estimadas, neste trabalho, as taxas de geração de viagens para professores e funcionários das instituições de ensino superior.

\section{AGRADECIMENTOS}

Os autores agradecem à Rede Ibero-Americana de Estudo em Polos Geradores de Viagens - REDPGV, pelo apoio financeiro para a realização da pesquisa e à Fundação de Amparo à Pesquisa do Estado de Minas Gerais - FAPEMIG, pela concessão da bolsa de mestrado à primeira autora.

\section{REFERÊNCIAS}

Andrade, E. P. e Portugal, L. S. (2012) Geração de viagens em PGVs. In: Portugal, L. S. (eds.) Polos geradores de viagens orientados a qualidade de vida e ambiental: modelos e taxas de geração de viagens. Editora Interciência. Rio de Janeiro.

Bertazzo, A. B. S. (2008) Estimativa e avaliação do padrão de viagens geradas para instituições de ensino médio. $198 \mathrm{f}$. Dissertação (Mestrado). Departamento de Engenharia Civil e Ambiental - Universidade de Brasília, Brasília, DF.

Bertazzo, A. B. S.; Galarraga, J.; Herz, M. e Jacques, M. A. P. (2012) Estabelecimentos de ensino. In: PortugaL, L. S. (eds.) Polos geradores de viagens orientados a qualidade de vida e ambiental: modelos e taxas de geração de viagens. Editora Interciência. Rio de Janeiro.

BRASIL (1997) Código de Trânsito Brasileiro. Lei ño 9.503 de 23 de setembro de 1997. Disponível em: www.denatran.gov.br/ctb.htm>. Acesso em: 14 abr. 2012.

ITE (2008) Trip Generation: An ITE Informational Report. 8th Edition, Washington, DC. 
Jacques, M. A. P.; Bertazzo, A.; CalarragA, J. e Herz, M. (2011)

Polos geradores de viagens orientados à qualidade de vida e ambiental: Estabelecimentos de ensino. Cadernos ITE. Versão preliminar: out. 2011. Disponível em:

www.redpgv.coppe.ufrj.br/index.php?option=com_phocadownlo ad\&view=file\&id=119\%3Acaderno-estabelecimeNtos-de-ensino-17.10.11-versao-revisada\&Itemid=99 \&lang=br $>$. Acesso em: 14 abr. 2012.

Paula, A. F. F. C. (2013) Taxas de geração de viagens para instituições privadas de ensino superior de Uberlândia, MG. 96 f. Dissertação (Mestrado), Faculdade de Engenharia Civil, Universidade Federal de Uberlândia.

Paula, A. F. F. C.; Sorratini, J. A. e Silva, T. P. (2014) Padrão de viagens geradas por instituições de ensino superior privadas da cidade de Uberlândia. JTL/RELIT, Journal of Transport

Literature, Manaus, v. 8, n. 3, p. 107-138. DOI: 10.1590/S223810312014000300006.

Souza, S. C. F. de. (2007) Modelos para estimativa de viagens geradas por Instituições de Ensino Superior. 170 f. Dissertação (Mestrado). Departamento de Engenharia Civil e Ambiental Universidade de Brasília, Brasília, DF. 